\title{
Factors predicting quality of life for coronary artery disease patients after percutaneous coronary intervention
}

\author{
Aem-orn Saengsiri, Sureeporn Thanasilp, Sunida Preechawong \\ Faculty of Nursing, Chulalongkorn University, Bangkok 10330, Thailand
}

\begin{abstract}
Background: A clear understanding of factors affecting patients' perception of quality of life (QOL) would be useful for improving continuous care in coronary artery disease (CAD) patients.

Objective: To examine the causal relationships between cardiac self-efficacy, social support, left-ventricular ejection fraction (LVEF), angina, dyspnea, depression, vital exhaustion, functional performance, and QOL in CAD patients experiencing postpercutaneous coronary intervention (post-PCI).

Methods: We used a research survey for causal analysis design to explore the theoretical linkage, guided by the revised Wilson and Cleary model, between QOL interest variables and patient QOL. The 303 subjects were all post-PCI CAD patients. All participants completed the following surveys: (1) a demographic data questionnaire, (2) a QOL Index (Cardiac version IV), (3) the Center for Epidemiologic Studies Depression Scale, (4) the Cardiac Self-efficacy Scale, (5) the Social Support Questionnaire, (6) the Rose Questionnaire for angina, (7) the Rose Dyspnea Scale, (8) the SF-36: vitality subscale, and (9) the Functional Performance Inventory Short-Form, with reliability ranging from 0.72 to 0.98 . Data were analyzed using a linear structural relationship analysis.

Results: The postulated model was found to fit the empirical data and explained $54 \%$ of the variance in quality of life $\left(\chi^{2}=1.90, \mathrm{df}=3, p=0.59, \chi^{2} / \mathrm{df}=0.63\right.$, root mean square error of approximation $=0.00$, Goodness of Fit Index $=0.99$, Adjusted Goodness of Fit Index $=0.98$ ). Social support, depression, and vital exhaustion were found to significantly and directly affect the QOL of post-PCI CAD patients. Cardiac self-efficacy was the only variable that had an indirect effect on quality of life $(\beta=0.21, p<0.001)$.

Conclusion: Health care providers should be aware of the significant effects of social support, depression, vital exhaustion, and self-efficacy on QOL, and develop appropriate nursing interventions to improve quality of life in post-PCI CAD patients.
\end{abstract}

Keywords: Cardiac self-efficacy, coronary artery disease, depression, quality of life, social support, vital exhaustion

Impaired quality of life has increasingly become the most significant health outcome for patients with chronic diseases such as coronary artery disease (CAD). Most research conducted into the supportive care of CAD patients has been focused on effectiveness of treatment, and, as a result, there has been little research into the CAD population's postpercutaneous coronary intervention (post-PCI) quality of life. Thus, assessment of quality of life in this study was not intended to measure the effectiveness of treatment, but was used to determine the effects on those other areas of life that specifically relate to a person's health [1].

Correspondence to: Sureeporn Thanasilp, Faculty of Nursing, Chulalongkorn University, Bangkok 10330, Thailand.

E-mail: sureeporn.t@chula.ac.th
CAD can affect any coronary artery. For example, atherosclerosis disease is a form of CAD that causes reduced blood flow and oxygen supply to the heart muscle, inducing a symptomatic cardiac event that threatens patients' lives [2]. At present, revascularizations by PCI and coronary artery bypass grafts (CABG) are both effective treatments for symptomatic cardiac events, but clinical evidence has indicated that PCI patients with recurrent angina had a significantly lower quality of life than CABG patients $[3,4]$. However, further investigation is required to study the factors that affect quality of life in post-PCI CAD patients, especially after one year of recovery from wound pain that might have since affected their quality of life.

In Thailand, most CAD-related research has investigated the effects of revascularization treatment on quality of life, and findings indicate that patients' 
quality of life increased for a short period of time post-treatment [5-7]. One study followed up with CAD patients one year after participating in an intensive lifestyle management program, but quality of life had not significantly improved [7]. Thus far, no study has explored the factors affecting quality of life for CAD patients; however, understanding these factors is necessary to develop specific nursing interventions for post-PCI patients. Moreover, a clear understanding of the factors predicting quality of life is important for designing nursing interventions that are specifically tailored for post-PCI CAD patients.

Based on analysis of literature reviews, psychological symptoms (such as depression and anxiety), angina, vital exhaustion, and dyspnea have been observed to have the most significant influence on quality of life in people with CAD [8-11]. Other variables such as sex, social support, personality, and socioeconomic factors have also been identified as significant in predicting quality of life for CAD patients [11-13]. In summary, the relationships between the factors that affect quality of life are complicated and difficult to understand. If the causes for low quality of life scores are identified, then specific interventions to improve quality of life among CAD patients can be developed from them [14]. Many theories have attempted to explain the different factors affecting quality of life. Wilson and Cleary's model is widely used in quality of life literature because it merges biomedical and social science paradigms. Ten years after its introduction, Ferrans and colleagues revised the Wilson and Cleary model, suggesting that biological function as an antecedent of quality of life is influenced by the characteristics of both individuals and their environment. Wilson and Cleary also encouraged application of their revised model to a specific clinical population (Figure 1).

To fill the gap in current knowledge of the factors affecting quality of life in CAD patients, this study aims to explain the relationship between cardiac selfefficacy, social support, biological and physiological (LVEF) symptoms of angina, dyspnea, depression, vital exhaustion, functional performance, and quality of life in post-PCI CAD patients. A clear understanding of the multiple factors affecting patients' perception of their quality of life will facilitate the design of an optimal and effective nursing intervention program for maintaining and improving quality of life in post-PCI CAD patients. The proposed relationships between variables and concepts are defined in Figure 2.

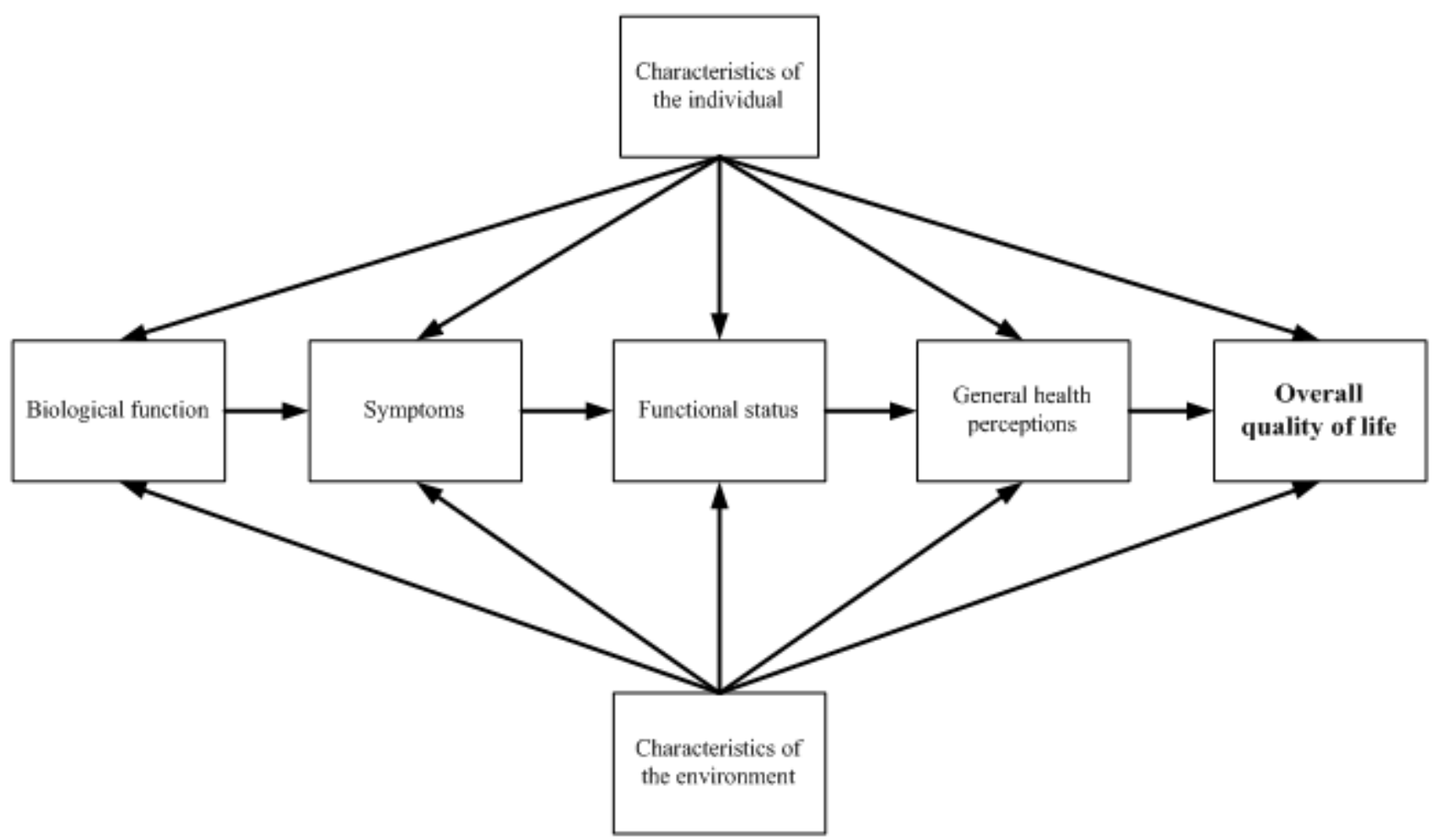

Figure 1. The revised Wilson and Cleary model, adapted from "Linking clinical variables with health-related quality of life: a conceptual model of patient outcome,” Wilson IB and Clearly PD, 1995 


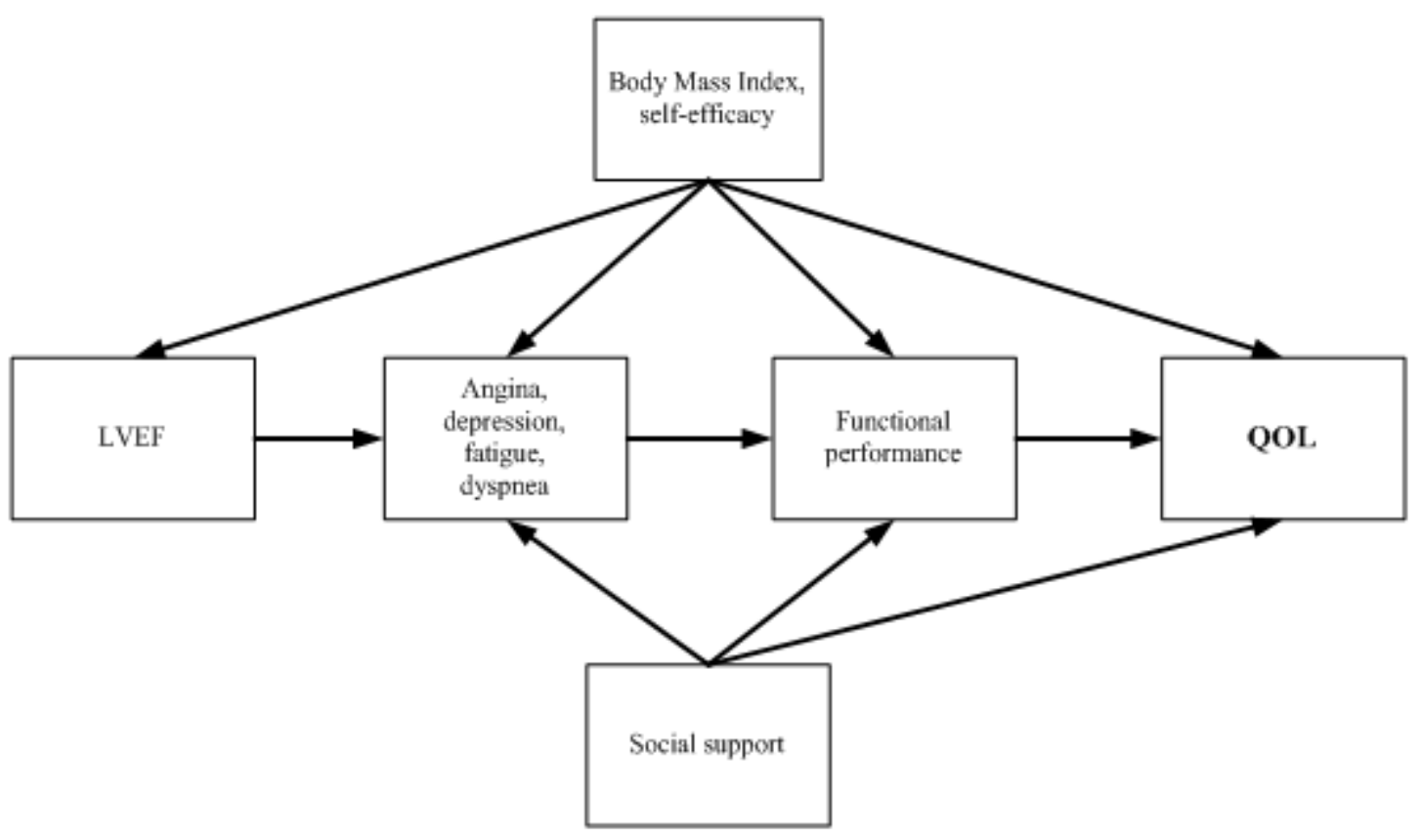

Figure 2. Schematic for this study

\section{Materials and methods Design}

A research survey for causal analysis was conducted among the CAD population at the outpatient departments of five tertiary hospitals, from August 2011 to February 2013. This study was approved by the Institutional Review Board of the Faculty of Medicine, Chulalongkorn University. Each of the potential participants were fully informed about the study objectives and provided with information regarding what would be involved for participants. Furthermore, participants were informed that their participation was voluntary, and that they could terminate their participation at any time without repercussions. Those willing to participate were asked to sign a consent agreement before taking part in the study.

\section{Subjects}

The participants involved in the study were patients recruited from out-patient cardiac clinics who met the following inclusion criteria; (1) having been diagnosed with CAD in at least one vessel with more than 50\% stenosis; (2) having a history of CAD for greater than or equal to one year; (3) being over twenty years of age; (4) having had PCI treatment for longer than 12 months; (5) having a stable angina pectoris class I-III; (6) being able to communicate in and understand the Thai language; and (7) being willing to participate in this study.

The sample size was selected using parameter estimation [15]. The adequate sample size for path analysis is between $5-20$ subjects for each parameter [15-16]. In this study, the postulated model contained 37 free parameters, and so a sample size of 185-740 was the minimum requirement to match the complexity of the path model. The 303 participants in this study were recruited from a total sample size of 334 . Complete data was collected from all 303 participants, and used for the data analysis.

\section{Instruments}

The instruments used in this study included the following nine questionnaires (Thai versions): (1) the Quality of Life Index, Cardiac Version IV; (2) the Center for Epidemiologic Studies Depression Scale (CES-D); (3) the Cardiac Self-Efficacy Scale (C-SES); (4) the Social Support Questionnaire (SSQ); (5) the Rose Questionnaire for angina; (6) the Rose Dyspnea Scale (RDS); (7) SF-36: vitality subscale (VT); (8) the Functional Performance Inventory, Short-Form (FPI-SF), and (9) a personal data section. Information for all of these instruments is shown in

\section{Table 1.}

1. The Quality of Life Index, Cardiac Version IV. Quality of life was measured using 70 items of the 
Quality of Life Index Cardiac version IV, Thai version [7]. Each item used a six-point Likert rating scale. Scores were calculated for overall quality of life in four domains: health and functioning (15 items), social and economic (8 items), psychological/spiritual (7 items), and family (5 items). High scores indicated a better quality of life.

2.The Center for Epidemiologic Studies Depression Scale (CES-D). The Thai version of the CES-D is a depression scale using 20 items that assess perceived mood and level of functioning within the past seven days. Response categories indicated the frequency of occurrence of each item, and were scored on a 4-point scale, ranging from 0 (rarely, or none of the time) to 3 (most, or all of the time). Final scores ranged from 0 to 60 , with higher scores indicating increased severity of depression. Cut-off scores for depression available for Thai people were 19 or higher [17].

3. The Cardiac Self-Efficacy Scale (C-SES). The C-SES used in this study had 14 items, measuring two sub-dimensions of self-efficacy: control of symptoms (8 items) and maintenance of function (6 items) [18]. Our team translated and included one additional item. The items were first scored on a 5point Likert scale ranging from 0 to 4 , followed by summation. Higher scores indicated a greater level of cardiac self-efficacy in maintaining function.

4. The Social Support Questionnaire (SSQ). This questionnaire was developed by Schaefer, Coyne, and Larzarus, and was modified by Hanucharurnkul for cancer patients in 1988, and first used by Khuwatsamrit et al. with cardiac patients [19]. This questionnaire consists of 21 items that measure social support received from three sources: family, friends, and healthcare providers. The SSQ used in this study had a five-point Likert-like scale from 0 to 4 , and scores ranged from 0 to 84 . Higher scores indicated a higher level of social support.

5. The Rose Questionnaire for angina. This questionnaire is widely used in epidemiological study for assessing angina, and it has been translated into many languages [20]. The Thai version with a modified scale was used in this study. This instrument consists of eight items and scores ranging from 0 to 8 , with $0-1$ presenting no chest pain, $2-7$ borderline chest pain, and 8 indicating chest pain.

6. The Rose Dyspnea Scale (RDS). In this study, the RDS was used to assess dyspnea [21]. This scale surveys the patient's level of dyspnea with common activities. The scale consists of four items, with scores ranging from 0 to 4 , where 0 indicates no dyspnea with activity, and increasing scores indicate greater limitations because of dyspnea. This instrument was translated into Thai for the purpose of this study.

7.The SF-36: vitality subscale (VT). Vital exhaustion was assessed using a Thai version of the SF-36 vitality subscale [22]. This subscale consists of four items, with scores ranging from 1 to 6 , where higher values indicate greater vital exhaustion.

8. The Functional Performance Inventory ShortForm (FPI-SF). This inventory assesses functional performance in terms of the day-to-day activities that $\mathrm{CAD}$ patients engage in in their lives to meet basic needs, fulfill usual roles, and maintain their health. The Thai version of the FPI-SF was utilized [23] and consists of 40 items ranging on a scale from 1 (activity can be performed easily) to 4 (activity can no longer be performed for health reasons). The FPISF consists of six subscales grouped into three types of daily life activity (ADL): (1) basic ADL (BADL): bodily care and physical exercise; (2) instrumental ADL (IADL): household maintenance; and (3) advanced ADL (AADL): recreation, spiritual activities, and social activities, with higher scores indicating greater functional status.

\section{Statistical analysis}

Descriptive statistics including frequencies, means, and standard deviations were used to describe the demographic data and variables in the path model. The assumption analysis was conducted to include normality of distribution, linearity of relationship, homogeneity of variance, and multicollinearity. A Pearson Product Moment correlation was used to test for bivariate relationships among the pairs of variables, and to assess multicollinearity among the independent variables. The postulated model was tested using a path analysis that presented the idea that the variation in quality of life could depend on nine predictive variables: cardiac self-efficacy, social support, LVEF, angina, dyspnea, depression, vital exhaustion, and functional performance. The significance level of this study was set at 0.05 .

Two steps of analysis were used to find better-fit models in this study. The first step was analysis of the postulated model, and the second step was modification, by deletion of the significant path from the postulated model that fitted the final model. Furthermore, the $\chi^{2}$ test, the Goodness of Fit Index 
(GFI), the Adjusted Goodness of Fit Index (AGFI), and the root mean square error of approximation (RMSEA) were tested to assess the adequacy of the model fit with the empirical data. In the case of inadequate fit to the data, the model was adjusted under the modification index and theoretical meaning until an adequate fit was obtained. A 'good fit' was determined according to the following criteria: $p>0.05$, RMSEA < 0.05, GFI > 0.9, AGFI > 0.9, NFI $>0.9$, and CFI $>0.9$. SPSS (version 11.5; SPSS, Chicago, IL, USA) and LISREL (version 8.72) were used for all of the analyses in this study.

\section{Results \\ Participant demography}

For the study period, the mean age of the 303 participants was 61.17 years $(S D=10.96$, range $=$ 35-87), and three out of four participants were men (73.6\%). The majority of participants was part of a couple $(81.2 \%)$ and had completed primary or elementary education (52.2\%). Moreover, some of the participants were unemployed (31.3\%), some worked in the field of agriculture (17.8\%), and some were government officials (15.8\%). Approximately half of the participants (46.2\%) had a monthly family income of less than 10,000 Thai Baht (1 US dollar $=31$ Thai Baht). The findings regarding the demographic characteristics of the participants are summarized in Table 2.

\section{Model testing}

The present study showed 45 correlations between variables with significance level 0.01 among 20 pairs, and no significance among 25 pairs. The Pearson correlation ranged from -0.16 to 0.57 . The strongest correlation was between depression and vital exhaustion ( $r=0.57, p<0.01$ ), and the weakest correlations were between angina and vital exhaustion $(\mathrm{r}=-0.16, p<0.01)$, and dyspnea and quality of life $(\mathrm{r}$ $=-0.16, p<0.01)$. The correlation metric of all variables is presented in Table 3 .

The paths of this model are shown in Table 4. The test model was comprised of two exogenous variables (cardiac self-efficacy and social support), and seven endogenous variables (LVEF, angina, dyspnea, vital exhaustion, depression, functional performance, and quality of life). Path analysis was used to validate the relationships between the variables regarding quality of life. The test model was not found to be relevant to the evidence. Thus, the model was modified repeatedly (four times) based on suggested modification indices until it was determined to fit adequately with empirical data. Results of the direct, indirect, and total effects of quality of life in post-PCI CAD patients are presented in Table 5 .

The final model in this study was analyzed by using $\mathrm{a} \chi^{2}$ test $=1.90 ; \mathrm{df}=3 ; p=0.59 ;$ RMSEA $=0.00$, GFI $=0.99$; AGFI $=0.98$, as shown in Figure 3. Fiftyfour percent of total variance in quality of life was predicted by four significant factors (cardiac selfefficacy, social support, depression, and vital exhaustion). LVEF, angina, dyspnea, and functional performance were not found to significantly affect quality of life.

Table 1. Summary of instruments, variable, and reliability

\begin{tabular}{|c|c|c|c|}
\hline & Variable & Validity & $\begin{array}{l}\text { Reliability } \\
\text { Cronbach's } \alpha\end{array}$ \\
\hline 1. Quality of Life Index-Cardiac Version & Quality of life & $\begin{array}{l}\text { Goodness of fit } \\
\chi^{2}=1.32, \chi^{2} / \mathrm{df}=0.50, p=0.52, \mathrm{RMSEA}=0.00\end{array}$ & 0.98 \\
\hline $\begin{array}{l}\text { 2. The Center for Epidemiologic Studies } \\
\text { Depression Scale (CES-D) }\end{array}$ & Depression & $\begin{array}{l}\text { Goodness of fit } \\
\chi^{2}=1.50, \chi^{2} / \mathrm{df}=1.50, p=0.22, \mathrm{RMSEA}=0.04\end{array}$ & 0.82 \\
\hline 3. Cardiac self-efficacy scale & Self-efficacy & $\begin{array}{l}\text { Goodness of fit } \\
\chi^{2}=0, \chi^{2} / \mathrm{df}=0.00, p=1.00, \text { RMSEA }=0.00\end{array}$ & 0.87 \\
\hline 4. The Social Support Questionnaire (SSQ) & Social support & $\begin{array}{l}\text { Goodness of fit } \\
\chi^{2}=0, \chi^{2} / \mathrm{df}=0.00, p=1.00, \mathrm{RMSEA}=0.00\end{array}$ & 0.89 \\
\hline 5. The Rose Questionnaire for angina & Angina & $\begin{array}{l}30.3 \% \text { sensitivity, } 83.9 \% \text { specificity } \\
\text { (Udol and Mahanonda, 2000) }\end{array}$ & 0.86 \\
\hline 6. The Rose Dyspnea Scale (RDS) & Dyspnea & $\mathrm{CVI}=1.0$ & 0.81 \\
\hline 7. SF-36: vitality subscale (VT) & Vitality & $\begin{array}{l}\text { Inter item correlation }=0.4 \\
\text { (Krittayaphong et al., 2000) }\end{array}$ & 0.72 \\
\hline $\begin{array}{l}\text { 8. Functional Performance Inventory } \\
\text { Short-Form (FPI-SF) }\end{array}$ & $\begin{array}{l}\text { Functional } \\
\text { performance }\end{array}$ & $\begin{array}{l}\text { Goodness of fit } \\
\chi^{2}=9.25, \chi^{2} / \mathrm{df}=1.54, p=0.16, \mathrm{RMSEA}=0.04\end{array}$ & 0.91 \\
\hline
\end{tabular}

RMSEA = root mean square error of approximation 
Table 2. Demographic characteristics of the study participants $(n=303)$

\begin{tabular}{|c|c|c|}
\hline Characteristics & Number & Percentage \\
\hline \multicolumn{3}{|l|}{ Age (years) } \\
\hline $30-44$ & 19 & 6.3 \\
\hline $45-59$ & 113 & 37.3 \\
\hline $60-74$ & 131 & 43.2 \\
\hline$>75$ & 40 & 13.2 \\
\hline \multicolumn{3}{|l|}{ Sex } \\
\hline Male & 223 & 73.6 \\
\hline Female & 80 & 26.4 \\
\hline \multicolumn{3}{|l|}{ Marital status } \\
\hline Marriage & 246 & 81.20 \\
\hline Widowed//separated/divorced & 47 & 15.50 \\
\hline Single & 10 & 3.30 \\
\hline \multicolumn{3}{|l|}{ Education } \\
\hline Primary/elementary education & 158 & 52.20 \\
\hline Secondary education & 61 & 20.10 \\
\hline High school & 21 & 6.90 \\
\hline Diploma/certificate & 2 & 0.60 \\
\hline Bachelor’s degree or higher & 61 & 20.10 \\
\hline \multicolumn{3}{|l|}{ Occupation } \\
\hline Unemployed/ housewife & 95 & 31.30 \\
\hline Agriculturist & 54 & 17.80 \\
\hline Government official & 48 & 15.80 \\
\hline Business & 32 & 10.60 \\
\hline Employed & 28 & 9.20 \\
\hline Other & 46 & 15.20 \\
\hline \multicolumn{3}{|l|}{ Family income/month (Baht) } \\
\hline$\leq 5000$ & 84 & 27.7 \\
\hline $5,001-10,000$ & 56 & 18.5 \\
\hline $10,001-15,000$ & 41 & 13.5 \\
\hline $15,001-20,000$ & 33 & 10.9 \\
\hline$>20,000$ & 89 & 29.4 \\
\hline
\end{tabular}

Table 3. Bivariate relationships among LVEF, self-Efficacy, social support, angina, dyspnea, vitality, depression, functional performance, and quality of life

\begin{tabular}{|c|c|c|c|c|c|c|c|c|c|}
\hline Variable & $\begin{array}{l}\text { Cardiac } \\
\text { Self- } \\
\text { efficacy }\end{array}$ & $\begin{array}{l}\text { Social } \\
\text { support }\end{array}$ & LVEF & Angina & Dyspnea & Depression & $\begin{array}{l}\text { Vital } \\
\text { exhaustion }\end{array}$ & $\begin{array}{l}\text { Functional } \\
\text { performance }\end{array}$ & $\begin{array}{l}\text { Quality } \\
\text { of life }\end{array}$ \\
\hline $\begin{array}{l}\text { Cardiac } \\
\text { Self-efficacy }\end{array}$ & 1.00 & & & & & & & & \\
\hline Social support & $.38 * *$ & 1.00 & & & & & & & \\
\hline LVEF & .11 & -.09 & 1.00 & & & & & & \\
\hline Angina & -.02 & -.07 & -.04 & 1.00 & & & & & \\
\hline Dyspnea & $-.22 * *$ & .01 & -.11 & .08 & 1.00 & & & & \\
\hline Depression & $-.43^{* *}$ & $-.22 * *$ & -.08 & .07 & $.29 * *$ & 1.00 & & & \\
\hline $\begin{array}{l}\text { Vitality } \\
\text { exhaustion }\end{array}$ & $.45^{* *}$ & $.23 * *$ & .06 & $-.16^{* *}$ & $-.29 * *$ & $-.57 * *$ & 1.00 & & \\
\hline $\begin{array}{l}\text { Functional } \\
\text { performance }\end{array}$ & $.37 * *$ & .11 & .05 & -.01 & $-.30 * *$ & $-.26^{* *}$ & $.30 * *$ & 1.00 & \\
\hline Quality of life & $.55^{* *}$ & $.50 * *$ & -.01 & -.06 & $-.17 * *$ & $-.53 * *$ & $.54 * *$ & $.30 * *$ & 1.00 \\
\hline
\end{tabular}


Table 4. Standardized path coefficients, standard error (SE), and $t$-value of parameters of the final model of HRQOL in CAD patients $(n=303)$

\begin{tabular}{|c|c|c|c|c|c|c|}
\hline Path diagram & & & \multicolumn{2}{|c|}{$\begin{array}{c}\text { Standardized } \\
\text { path coefficients }\end{array}$} & $\mathrm{SE}$ & $t$ \\
\hline \multicolumn{7}{|l|}{$\overline{\text { BETA }}$} \\
\hline LVEF & $\rightarrow$ & angina & -0.049 & -0.001 & 0.001 & -0.844 \\
\hline LVEF & $\rightarrow$ & dyspnea & -0.072 & -0.002 & 0.002 & -1.270 \\
\hline LVEF & $\rightarrow$ & depression & -0.045 & -0.001 & 0.002 & -0.853 \\
\hline LVEF & $\rightarrow$ & Vital exhaustion & 0.027 & 0.000 & 0.001 & 0.521 \\
\hline LVEF & $\rightarrow$ & QOL & -0.040 & 0.000 & 0.000 & -1.000 \\
\hline Angina & $\rightarrow$ & depression & 0.041 & 0.068 & 0.083 & 0.811 \\
\hline Angina & $\rightarrow$ & functional performance & 0.029 & 0.053 & 0.097 & 0.549 \\
\hline Angina & $\rightarrow$ & QOL & 0.020 & 0.008 & 0.016 & 0.508 \\
\hline Dyspnea & $\rightarrow$ & functional performance & -0.203 & -0.281 & 0.077 & $-3.693 * * *$ \\
\hline Dyspnea & $\rightarrow$ & QOL & 0.028 & 0.009 & 0.013 & 0.649 \\
\hline Depression & $\rightarrow$ & functional performance & -0.025 & -0.028 & 0.074 & -0.383 \\
\hline Depression & $\rightarrow$ & QOL & -0.239 & -0.060 & 0.012 & $-4.793 * * *$ \\
\hline Vital exhaustion & $\rightarrow$ & functional performance & 0.109 & 0.332 & 0.202 & 1.644 \\
\hline Vital exhaustion & $\rightarrow$ & QOL & 0.235 & 0.159 & 0.034 & $4.629 * * *$ \\
\hline Functional performance & $\rightarrow$ & QOL & 0.071 & 0.016 & 0.010 & 1.615 \\
\hline \multicolumn{7}{|l|}{ GRAMMA } \\
\hline Self-efficacy & $\rightarrow$ & LVEF & 0.162 & 2.897 & 1.101 & $2.632^{* *}$ \\
\hline Self-efficacy & $\rightarrow$ & angina & 0.015 & 0.006 & 0.023 & 0.245 \\
\hline Self-efficacy & $\rightarrow$ & dyspnea & -0.252 & -0.122 & 0.030 & $-4.135^{* * *}$ \\
\hline Self-efficacy & $\rightarrow$ & depression & -0.403 & -0.239 & 0.034 & $-7.122^{* * *}$ \\
\hline Self-efficacy & $\rightarrow$ & Vital exhaustion & 0.419 & 0.092 & 0.012 & $7.460 * * *$ \\
\hline Self-efficacy & $\rightarrow$ & functional performance & 0.287 & 0.193 & 0.042 & $4.575^{* * *}$ \\
\hline Self-efficacy & $\rightarrow$ & QOL & 0.205 & 0.030 & 0.007 & $4.113^{* * *}$ \\
\hline Social support & $\rightarrow$ & LVEF & -0.149 & -2.758 & 1.135 & $-2.429 *$ \\
\hline Social support & $\rightarrow$ & angina & -0.080 & -0.030 & 0.023 & -1.282 \\
\hline Social support & $\rightarrow$ & dyspnea & 0.099 & 0.049 & 0.030 & 1.623 \\
\hline Social support & $\rightarrow$ & depression & -0.071 & -0.043 & 0.035 & -1.251 \\
\hline Social support & $\rightarrow$ & Vital exhaustion & 0.075 & 0.017 & 0.013 & 1.344 \\
\hline Social support & $\rightarrow$ & functional performance & -0.032 & -0.022 & 0.039 & -0.565 \\
\hline Social support & $\rightarrow$ & quality of life & 0.307 & 0.047 & 0.007 & $7.074 * * *$ \\
\hline
\end{tabular}

${ }^{*} p<0.05,{ }^{* *} p<0.01,{ }^{* * *} p<0.001$

Use of the revised Wilson and Cleary model in addition to evidence support from this study revealed that the four variables that had the most powerful direct effect on the quality of life of post-PCI CAD patients were social support, depression, vital exhaustion, and cardiac self-efficacy, and the standardized path coefficient values for these variables were $0.31,0.24$, 0.23 , and 0.21 , respectively. However, self-efficacy was found to be the one variable in this study that had a powerful, indirect effect on quality of life $(0.21, p<$ $0.001)$. The findings of this study indicate that postPCI CAD patients who received more social support, showed fewer symptoms of depression and vital exhaustion, and who demonstrated higher selfefficacy, appeared to experience a better quality of life.

\section{Discussion}

Understanding quality of life has become increasingly important regarding the clinical outcomes of healthcare research. It has therefore become important to describe fully the different factors that affect quality of life. The results of this study provide valuable information regarding post-treatment health within the CAD population that could be used to affect the lives of patients positively. Additionally, to obtain appropriate and scientifically reliable information, this study used disease-specific measures that could accurately reflect changes in quality of life in patients, and provide relevant information about this issue [24, 25]. The findings of the present study report that the postulated model adequately fits the empirical data and 


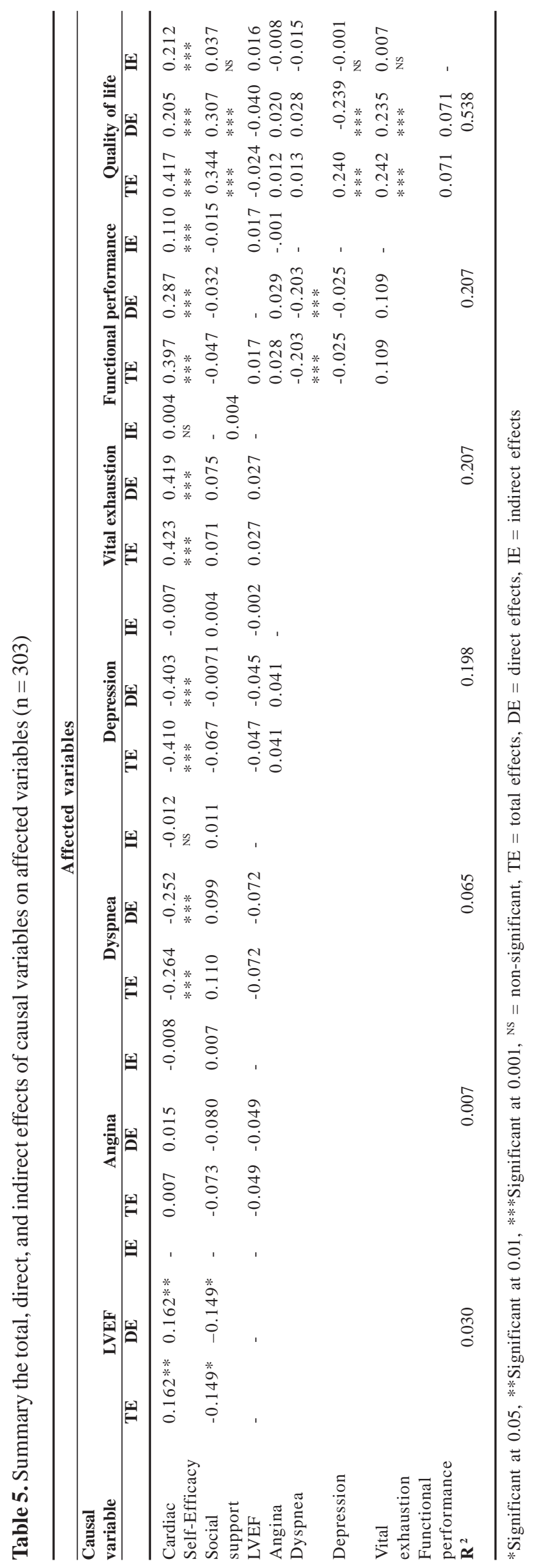




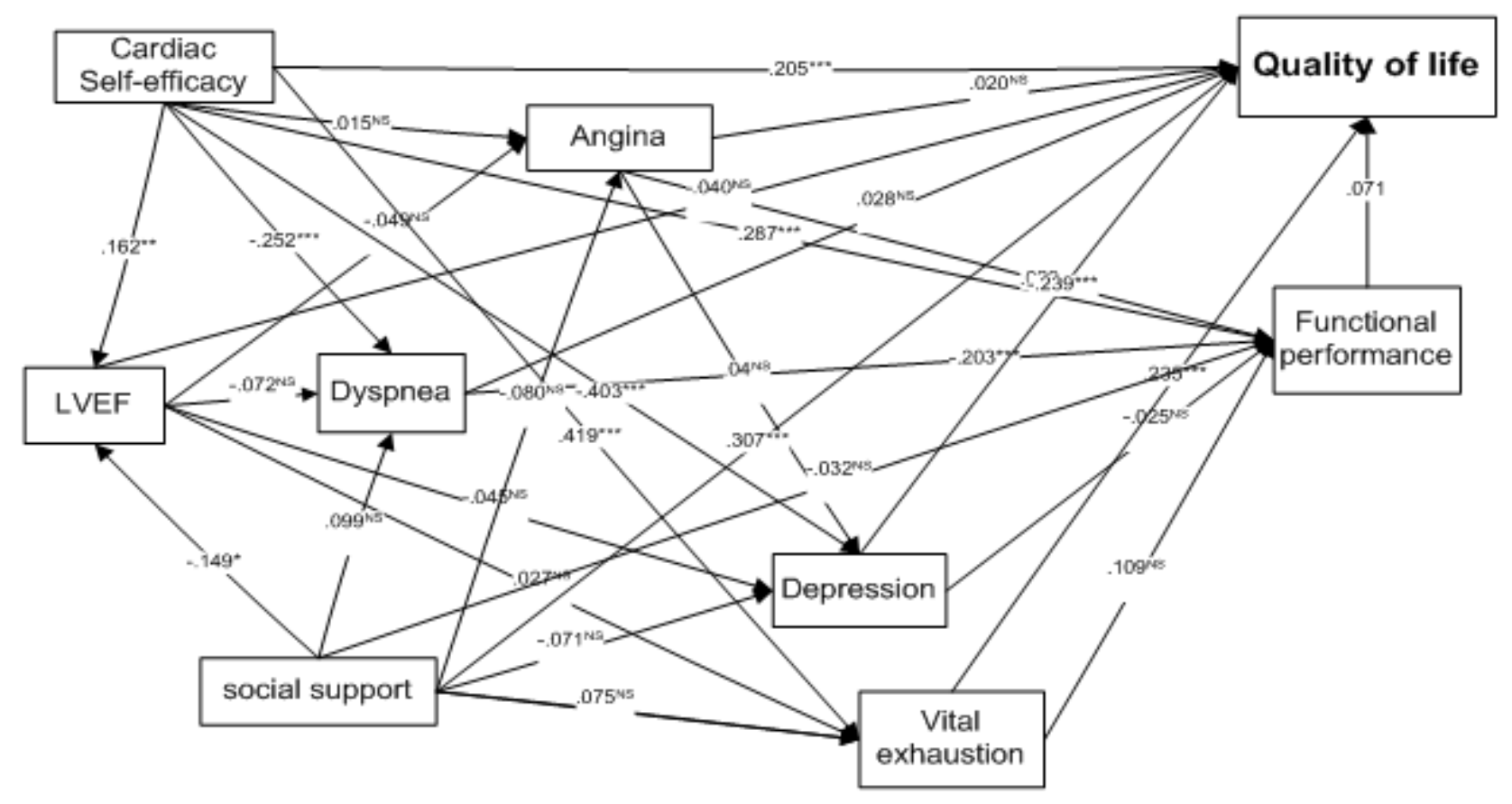

$$
\chi^{2}=1.90, \mathrm{df}=3, p=0.59, \text { RMSEA }=0.00
$$

Figure 3. The modified model of quality of life on CAD patients

explains $54 \%$ of the variance in quality of life by the factors of cardiac self-efficacy, social support, LVEF, angina, dyspnea, depression, vital exhaustion, and functional performance. This finding is relevant to a previous study by Hofer and his team, which investigated the quality of life model in CAD patients while including both biomedical factors and individual environmental characteristics. Overall, the model could sufficiently explain $49 \%$ of its variance [8].

A postulated path model for quality of life in postPCI CAD patients was tested in this study. It is noteworthy that the postulated model was found to fit the empirical data on the quality of life for the CAD patients. Although some research hypotheses were only partially supported, the model was still meaningful and useful for explaining the factors affecting quality of life among the patients. Finally, all of the variables in the model could be used to explain approximately $54 \%$ of the variance in quality of life.

The failure to find a significant relationship between functional performance, angina, dyspnea, and LVEF with quality of life may reflect the characteristic in which almost all of the participants in this study had a functional performance score higher than the mean score, fewer symptoms of angina and dyspnea, and normal LVEF. Hence, the post-PCI CAD patients in this study had a high level of competence in performing daily functions, which may explain the reduced variation in the factors affecting quality of life. However, in clinical practice, the assessment of LVEF might still be considerably useful for evaluating cardiac function, and other important symptoms experienced by CAD patients, which could be concerning, such as angina and dyspnea.

The results of this study indicate that the most important variable influencing quality of life is cardiac self-efficacy, as there was found to be a strong correlation between this variable and quality of life in the 303 CAD patients who participated. Consistent with previous findings from studies discussing the notion of cardiac self-efficacy, this study indicates that creative management care in CAD patients would be beneficial [26-29]. Most previous studies have found that cardiac self-efficacy has a strong relationship with dyspnea and is useful for assessing management care for pulmonary patients [30-32]. Also consistent with previous studies, self-efficacy was shown to have a strong relationship with depression [33-35]. This relationship can provide more information about management care [36] and help to promote healthy behavior [26] and physical activity [37] in CAD patients. 
Epidemiological evidence and reviews indicate that social support has been prospectively associated with adverse CAD [38]. In addition, a systematic review and meta-analysis also established that social support was important for the prognosis of CAD [39]. Furthermore, previous evidence showed that social support usually occurs with the prognosis of CAD, but that there were differences in the type of social support received by CAD patients [38]. However, these findings are incongruent with findings by Hofer et al., in that social support did not influence healthrelated quality of life in CAD patients [8].

Previous reviews have indicated that depression has a bidirectional relationship with CAD, and is an independent risk factor for the disease [38, 40]. The findings from this study were not consistent with previous studies into the structural equation model of quality of life, which indicate that depression has a negative, indirect effect on quality of life [8]. One possible reason for this discrepancy is that the majority of participants in this study were not found to be depressed (80.6\%), which might have affected the variance of this factor.

The findings of this study indicate that post-PCI CAD patients who displayed greater vital exhaustion had higher scores in the quality of life assessment, which did not support the hypothesis. Furthermore, a previous study by Pederson et al. found that vitality was still highly prevalent post-PCI and could be used to predict quality of life [9]. It should be noted that this is the first study examining vital exhaustion in Thai CAD patients. Nevertheless, in this study, two symptoms found to be prevalent in post-PCI CAD patients were depression and vital exhaustion. This information could be useful in aiding advanced practice nurses to design cardiac nursing interventions tailored to help manage release symptoms, and improve quality of life for post-PCI CAD patients.

While interpreting and using the findings of this study, there are limitations that need to be considered. Firstly, the participants in this study were all post-PCI CAD patients. In addition, the participants were from three, high-volume post-PCI CAD regions in Thailand, and therefore, the generalizability of the findings may be limited. Nevertheless, the researcher could still evaluate the effects of the variables highlighted in this study on each domain of quality of life, which may provide beneficial information that could be used to help ensure better quality of life outcomes for CAD patients.

\section{Acknowledgements}

The authors acknowledge the $90^{\text {th }}$ Anniversary of Chulalongkorn University Fund, the Ratchadaphiseksomphot Endowment Fund, for supplying a research grant throughout this study. No conflict of interest is reported for this study.

\section{References}

1. Ferrans CE, Zerwic JJ, Wilbur JE, Larson JL. Conceptual model of health-related quality of life. J Nurs scholarsh. 2005; 37:336-42.

2. Cassar A, Holmes DR Jr, Rihal CS, Gersh BJ. Chronic coronary artery disease: diagnosis and management. Mayo Clin Proc. 2009; 84:1130-46.

3. Barnason SA, Zimmerman LM, Brey B, Catlin S, Nieveen JL. Patterns of recovery following percutaneous coronary intervention: a pilot study. Appl Nurs Res. 2006; 19:31-7.

4. Durmaz T, Ozdemir O, Ozdemir BA, Keles T, Bayram NA, Bozkurt E. Factors affecting quality of life in patients with coronary heart disease. Turk J Med Sci. 2009; 39:343-51.

5. Khuwatsumrit K. Quality of life after coronary artery bypass graft. Master of Nursing Science (Adult Nursing) Thesis, Faculty of Graduate Studies, Mahidol University. 1996.

6. Polkanchanakorn P. Quality of life among patients with coronary artery disease before and after coronary stent implantation. Master of Nursing Science (Adult nursing) Thesis, Faculty of Graduate Studies, Mahidol University. 1998.

7. Saengsiri A, Wunsuwan R, Srimahachota S, Boonyaratavej S, Tanechpongtamb W, Tosukhowong P. Change in cell viability, reactive oxygen species production and oxidative stress in older patients with coronary heart disease under going lifestyle management program. Chula Med J. 2010; 54:81-97.

8. Hofer S, Benzer W, Alber H, Ruttmann E, Kopp M, Schussler G, et al. Determinants of health-related quality of life in coronary artery disease patients: a prospective study generating a structural equation model. Psychosomatics. 2005; 46:212-23.

9. Pedersen SS, Daemen J, van de Sande M, Sonnenschein K, Serruys PW, Erdman RA, et al. Type $\mathrm{D}$ personality exerts a stable, adverse effect on vital exhaustion in PCI patients treated with paclitaxeleluting stents. J Psychosom Res. 2007;62:447-453.

10. Appels A, van Elderen T, Bar F, van der Pol G, Erdman RA, Assman M, et al. Effects of a behavioural intervention on quality of life and related variables in 
angioplasty patients: results of the exhaustion intervention trial. J Psychosom Res. 2006; 61:1-7; discussion 9-10.

11. Skodova Z, van Dijk JP, Nagyova I, Rosenberger J, Ondusova D, Middel B, et al. Psychosocial predictors of change in quality of life in patients after coronary interventions. Heart Lung. 2011; 40:331-9.

12. Norris CM, Murray JW, Triplett LS, Hegadoren KM. Gender roles in persistent sex differences in healthrelated quality-of-life outcomes of patients with coronary artery disease. Gender Med. 2010; 7:330-9.

13. Han K, Lee S, Park E, Park Y, Cheol K. Structural model for quality of life of patient with chronic cardiovascular disease in Korea. Nurs Res. 2005; 54:85-96.

14. Wilson IB, Cleary PD. Linking clinical variables with health-related quality of life. a conceptual model of patient outcomes. JAMA. 1995; 273:59-65.

15. Hair JF, Black WC, Babin BJ, Anderson RE. Multivariate data analysis. New Jersey: Pearson; 2006.

16. Kline RB. Principles and practice of structural equation modeling. New York: The Guilford press; 1998.

17. Kuptniratsaikul V, Pekuman P. The study of the center for epidemiologic studies-depression scale (CES-D) in Thai people. Siriraj Hospital Gaz. 1997; 49:442-8.

18. Sullivan M, LaCroix A, Russo J, Katon W. Selfefficacy and self-reported functional status in coronary heart disease: a six-month prospective study. Psychosom Med. 1998; 60:473-8.

19. Khuwatsamrit K, Hanucharurnkul S, A.Chyun D, Panpakdee O, Tanomsup S, Viwatwongkasem C. Social support, self-efficacy, and adherence to selfcare requirements in patients with coronary artery disease. Thai J Nurs Res. 2006; 10:155-64.

20. Udol K, Mahanonda N. Comparison of the Thai version of the Rose questionnaire for angina pectoris with the exercise treadmill test. J Med Assoc Thai. 2000; 83:514-22.

21. Arnold SV, Spertus JA, Jones PG, Xiao L, Cohen DJ. The impact of dyspnea on health-related quality of life in patients with coronary artery disease: results from the PREMIER registry. Am heart J. 2009; 157: 1042-9.

22. Krittayaphong R, Bhuripanyo K, Raungratanaamporn O, Chotinaiwatarakul C, Chaowalit N, Punlee K, et al. Reliability of Thai version of SF-36 questionnaire for the evaluation of quality of life in cardiac patients. $\mathrm{J}$ Med Assoc Thai. 2000; 83(suppl 2):S130-6.

23. Sindhu S, Sriprasong S. A study of physical health conditions and level of activity during the recovering phase after discharge of acute myocardial infraction patients. Thai J Nurs Coun. 2001; 16:52-68.

24. Asadi-Lari M, Packham C, Gray D. Patients’ satisfaction and quality of life in coronary artery disease. Health Qual Life Outcomes. 2003; 1:57.

25. Asadi-Lari M, Gray D. Generic tools for measuring health-related quality of life in coronary artery disease. Expert Rev Pharmacoecon Outcomes Res. 2007; 7: 171-6.

26. Kang Y, Yang IS. Cardiac self-efficacy and its predictors in patients with coronary artery diseases. J Clin Nurs. 2013; 22:2465-73.

27. Sarkar U, Ali S, Whooley MA. Self-efficacy and health status in patients with coronary heart disease: findings from the heart and soul study. Psychosom Med. 2007; 69:306-12.

28. Millen JA, Bray SR. Promoting self-efficacy and outcome expectations to enable adherence to resistance training after cardiac rehabilitation. J Cardio Nurs. 2009; 24:316-27.

29. Senuzun F, Fadiloglu C, Burke LE, Payzin S. Effects of home-based cardiac exercise program on the exercise tolerance, serum lipid values and self-efficacy of coronary patients. Eur J Cardiovasc Prev Rehabil. 2006; 13:640-45.

30. Zimmerman BW, Brown ST, Bowman JM. A selfmanagement program for chronic obstructive pulmonary disease: relationship to dyspnea and selfefficacy. Rehabil Nurs. 1996; 21:253-7.

31. Scherer YK, Schmieder LE. The effect of a pulmonary rehabilitation program on self-efficacy, perception of dyspnea, and physical endurance. Heart Lung. 1997; 26:15-22.

32. Siela D. Use of self-efficacy and dyspnea perceptions to predict functional performance in people with COPD. Rehabil Nurs. 2003; 28:197-204.

33. Greco A, Steca P, Pozzi R, Monzani D, D’Addario M, Villani A, et al. Predicting depression from Illness severity in cardiovascular disease patients: selfefficacy beliefs, illness perception, and perceived social support as mediators. Int J Behav Med. 2013 Jan 25. [Epub ahead of print]

34. Steca P, Greco A, Monzani D, Politi A, Gestra R, Ferrari G, et al. How does illness severity influence depression, health satisfaction and life satisfaction in patients with cardiovascular disease? The mediating role of illness perception and self-efficacy beliefs. Psychol Health. 2013; 28:765-83.

35. Maeda U, Shen BJ, Schwarz ER, Farrell KA, Mallon S. Self-efficacy mediates the associations of social 
support and depression with treatment adherence in heart failure patients. Inter J Behav Med. 2013; 20: 88-96.

36. Howarter AD, Bennett KK, Barber CE, Gessner SN, Clark JM. Exercise self-efficacy and symptoms of depression after cardiac rehabilitation: predicting changes over time using a piecewise growth curve analysis. J Cardio Nurs. 2013 Feb 14. [Epub ahead of print]

37. Lapier TK, Cleary K, Kidd J. Exercise self-efficacy, habitual physical activity, and fear of falling in patients with coronary heart disease. Cardio Phys Ther J. 2009;
20:5-11.

38. Lett HS, Blumenthal JA, Babyak MA, Strauman TJ, Robins C, Sherwood A. Social support and coronary heart disease: epidemiologic evidence and implications for treatment. Psychosom Med. 2005; 67:869-78.

39. Barth J, Schneider S, Von KR. Lack of social support in the etiology and the prognosis of coronary heart disease: a systematic review and meta-analysis. Psychosom Med. 2010; 72:229-38.

40. Davidson KW. Depression and coronary heart disease. ISRN Cardiol. 2012; 2012: 743813. 